\title{
PERANAN POLA ASUH ORANG TUA TERHADAP KUALITAS HIDUP REMAJA PERKOTAAN
}

\author{
Pamela Hendra Heng ${ }^{1}$, Naomi Soetikno ${ }^{2}$, Amala Fahditia ${ }^{3}$ \\ ${ }^{1}$ Fakultas Psikologi, Universitas Tarumanagara, Jakarta \\ Email:pamelah@fpsi.untar.ac.id \\ ${ }^{2}$ Fakultas Psikologi, Universitas Tarumanagara, Jakarta \\ Email: naomis@fpsi.untar.ac.id \\ ${ }^{3}$ Program Studi Sarjana Psikologi, Universitas Tarumanagara, Jakarta \\ Email: amalaf98@gmail.com
}

Masuk : 19-06-2020, revisi: 27-10-2020, diterima untuk diterbitkan : 31-10-2020

\begin{abstract}
In an effort to improve the progress of the Indonesian nation, it is necessary to pay attention to all levels of society, especially the young people who will be the pillars of the Indonesian nation in the future. One fourth of Indonesia's population is children and adolescents. Other studies have shown that parenting can influence a child's level of selfconfidence, academic performance, and children's behavior. This research was to examine the "Role of Parents' Parenting towards Urban Adolescents' Quality of Life". A quantitative method with non-experimental was used and attended by 381 State High School students (SMAN), ages of 14-19 years in schools of X and Y in X city, namely 234 girls and 147 boys. Measuring instruments used are Youth Quality of Life (YQOL) and parenting measuring instruments that have been adapted. Based on the results of different tests on parenting parents with One-way Anova obtained values of $F=10,203, p=.000<.05$ for mothers' parenting, and $F=6,146, p=.000<.05$ for fathers' parenting, so there are significant differences between quality of life with parenting styles. The results showed that "authoritative" parenting has a high quality of life, where parents encourage, also provide limits, adolescents become independent individuals. Meanwhile, "neglectful" parenting has a low quality of life, lacks involvement in the lives of children, adolescents do not become independent individuals, less competent in socializing and lack of self-control.
\end{abstract}

Keywords: parenting, quality of life, urban youth

\begin{abstract}
ABSTRAK
Dalam upaya meningkatkan kemajuan bangsa Indonesia perlu diperhatikan semua lapisan masyarakat, khususnya para remaja yang akan menjadi tiang tonggak bangsa Indonesia di masa mendatang. Seperempat dari penduduk Indonesia merupakan anak-anak dan remaja. Penelitian lainnya menunjukkan bahwa pola asuh orangtua dapat mempengaruhi tingkat kepercayaan diri anak, performa dalam akademik, dan perilaku anaknya. Tujuan penelitian ini adalah untuk menguji "Peranan Pola Asuh Orang Tua terhadap Kualitas Hidup Remaja Perkotaan." Jenis penelitian ini menggunakan metode kuantitatif dengan non eksperimental dan ini diikuti oleh 381 siswa SMAN berusia 14-21tahun di sekolah X dan Y di kota X, yakni 234 wanita dan 147 pria. Alat ukur yang digunakan adalah Youth Quality of Life (YQOL) dan alat ukur pola asuh yang telah diadaptasi. Berdasarkan hasil uji beda pada pola asuh orangtua dengan Oneway Anova diperoleh nilai $F=10.203, p=.000<.05$ untuk pola asuh ibu, dan $F=$ 6.146, $p=.000<.05$ untuk pola asuh ayah, sehingga terdapat perbedaan yang signifikan antara kualitas hidup dengan pola asuh orangtua. Hasil penelitian menunjukkan, remaja dengan pola asuh orangtua yang "authoritative" memiliki kualitas hidup yang tinggi, dimana orang tua mendorong, juga memberikan batasan, remaja menjadi pribadi yang mandiri. Sementara, remaja dengan pola asuh orangtua yang "neglectful" memiliki kualitas hidup yang rendah, dimana kurang keterlibatan orangtua dalam kehidupan anak, remaja menjadi pribadi tidak mandiri, kurang kompeten bersosialisasi dan kurang pengendalian diri.
\end{abstract}

Kata Kunci: pola asuh, kualitas hidup, remaja perkotaan 


\section{PENDAHULUAN}

\section{Latar Belakang}

Kenakalan remaja yang sejak dulu dikenal dengan istilah tawuran semakin hari semakin menjurus kepada tindak kriminalitas yang dilakukan remaja di perkotaan. Generasi penerus bangsa, siswa-siswa yang ironisnya menjadi pembelajar yang baik tetapi melakukan penyimpangan perilaku yang menimbulkan keresahan bagi masyarakat Indonesia. Kejadian aksiaksi tawuran terjadi di berbagai tempat di Indonesia sepanjang tahun tanpa alasan. Beberapa kejadian yang merenggut nyawa terjadi di sekitar kota Jakarta. Tawuran antarkelompok siswa SMAN32 di Kawasan Kebayoran Lama, Jakarta Selatan, mengakibatkan Ari Haryanto tewas karena diduga sepuluh siswa yang menjadi pelaku menabrakan motor, membacok, memukuli dan menginjak-injak korban. Di Kota Bekasi, tepatnya di Jalan Raya Sumur Batu, Bantargebang terjadi tawuran yang menewaskan seorang siswa sekolah berinisial IP. Sementara SV, pelajar SLTA Bogor, yang berusia 15 tahun tewas akibat aksi brutal dengan sabetan clurit. Tawuran yang terjadi di Tangerang, adalah tawuran antarsuporter sepakbola yang membuat warga resah bahkan pedagang terpaksa segera menutup lapaknya karena terjadi saling serang, pelemparan benda-benda keras dan pembakaran kenderaan (Taufik, 2018). Banyak kejadian aksi tawuran itu dipicu hal-hal sepele misalnya postingan whatsapp yang dilakukan provokator dengan sengaja mencara gara-gara, kemudian berakhir dengan berduel atau tawuran berkelompok, bahkan merenggut nyawa temannya. Rini Nasution, salah satu dosen Antropologi Sosial Universitas Negeri Medan menilai ulah siswa tawuran adalah perilaku menyimpang yang bersifat destruktif. Sosiolog Paulus Wiroutomo menyatakan berdasarkan penelitian yang dilakukan di Johar Baru, Jakarta Pusat, tawuran wujud solidaritas antarwarga di Ibukota bisa terjadi antar-kelompok warga sesame kampung, antar-kelompok, antarkampung, atau antarsekolah. Tawuran semacam ini yang terjadi di berbagai tempat di Indonesia tidak dijumpai di negara lain. Dia menilai bahwa tawuran sebagai wujud solidaritas antarwarga itu tidak baik, karena dilakukan tidak pada tempatnya (Taufik, 2018). Adapun kasus kenakalan remaja yang terjadi adalah narkoba, pencurian, pergaulan bebas dan bahkan pembunuhan, (Asnizar, 2017).

Masalah kenakalan atau kejahatan remaja dapat dijelaskan melalui teori psikososial (Erikson, dalam Papalia et al., 2009). Remaja adalah individu yang berada pada rentang usia 11 hingga 21 tahun dan merupakan masa transisi dari anak-anak menuju dewasa (Papalia, Olds \& Feldman, 2009). Masa remaja ditandai adanya perubahan biologis, psikologis, dan sosial (Berk, 2014: Papalia, Olds \& Fredman, 2009). Dalam aspek biologis, remaja mengalami pubertas yang merupakan sebuah proses yang berujung pada kematangan seksual serta kemampuan untuk berkembang biak (Papalia et al., 2009). Hal yang juga menjadi ciri dari perkembangan kognitif remaja adalah egosentrisme yaitu pandangan bahwa orang lain memiliki pendapat yang sama dengan mereka (King, 2011). Remaja juga mampu melakukan hypothetical-deductive reasoning, yaitu kemampuan untuk mengembangkan, mempertimbangkan, dan menguji hipotesis. Remaja tidak hanya berpikir secara idealis dan abstrak, tetapi juga berpikir secara logis. Jika anak-anak cenderung memecahkan masalah berdasarkan percobaan (trial and error), remaja merancang rencana untuk memecahkan masalah dan menguji solusi secara sistematis (Santrock, 2015). Kemampuan ini menjadi alat dalam penyelesaian berbagai masalah di kehidupan sehari-hari.

Remaja menghadapi tiga masalah utama yaitu pengadaptasian nilai untuk diyakini, perkembangan identitas seksual yang memuaskan dan pekerjaan. Remaja yang gagal dalam pencarian jati dirinya akan memiliki keraguan terhadap dirinya dan kebingungan melakukan perannya sehingga dia menarik diri, mengalihkan diri ke arah yang negatif seperti memakai narkoba (Santrock, dalam Rice dan Dolgin, 2008). Masalah remaja juga mungkin disebabkan oleh adanya adolescent rebellion, yaitu ketika remaja bermasalah dalam gejolak emosi, menolak 
nilai dari orang dewasa, konflik dengan keluarga, perilaku ceroboh, dan merasa terasingkan dari masyarakat. Remaja yang memiliki kecenderungan rebel yang tinggi umumnya berasal dari keluarga yang bermasalah (Papalia et al., 2009).

Perilaku tawuran, anarkis, kenakalan dan kekerasan remaja tidak dapat dipisahkan dengan pola asuh orang tua serta kualitas hidup remaja. Menurut Kamus Besar Bahasa Indonesia (2008) pola berarti corak, model, sistem, dan cara kerja. Sementara itu, kata "asuh" berarti menjaga, merawat, mendidik, dan membimbing. Pengasuhan merupakan proses interaksi timbal balik antara orangtua dan anak serta penerapan serangkaian keputusan mengenai sosialisasi anak (Berns, 2013). Pola asuh merupakan pola yang ditunjukkan orangtua dalam menjalin relasi dengan anak-anak mereka (Arnett, 2013). Pola asuh merupakan bentuk interaksi antara orangtua dengan anak di mana orangtua memberikan didikan, bimbingan, serta pelindungan untuk anak tersebut agar dapat berkembang menjadi pribadi yang dewasa dan sesuai dengan norma masyarakat (Arifin \& Ummah, 2018). Pengasuhan bertujuan untuk menanamkan nilai dan memberi kesan positif kepada anak agar dapat digunakan dalam kehidupan (Olson, DeFrain, Skogrand, 2011). Maka melalui definisi pola asuh tersebut, disimpulkan bahwa pola asuh adalah sebuah proses interaksi yang terjalin antara orangtua dan anak dalam membentuk tingkah laku anak. Orang tua berperan penting dalam memberi kasih sayang, perlindungan dan menjadi model bagi anak (McDavid \& Garwood, dalam Ardini, 2012). Orangtua juga berperan untuk menyampaikan socialization, yaitu proses belajar berbagai aturan dan nilai yang berlaku dan harapan masyarakat dari anak. Faktor budaya, tingkat pendidikan orang tua dan cara orang tua menunjukkan kepedulian terhadap anak dapat mempengaruhi pola asuh (Chao, dalam Lawrence Erlbaum Associates, 2002). Orangtua juga bertanggung jawab merubah perilaku anak. Steinberg, Vandell, dan Bornstein (2011) menambahkan bahwa pengasuhan membentuk kualitas hubungan antara orangtua dan anak.

Menurut Baumrind (dalam Papalia et al., 2009) ada tiga jenis pola asuh yaitu authoritative, authoritarian, dan permissive. Melalui penelitian, Maccoby dan Martin (dalam Papalia et al., 2009) berhasil mengidentifikasi pola asuh keempat yakni neglectful. Orang tua yang mengasuh anaknya secara authoritative memberikan batasan sosial kepada anaknya dan menekankan kemandirian. Sementara itu, orang tua yang menganut pola asuh authoritarian menekankan kontrol dan kepatuhan pada anaknya. Orang tua dengan pola asuh permissive tidak menuntut, tidak mengontrol dan cenderung hangat dalam hubungan dengan anaknya. Sementara itu, orang tua dengan pola asuh neglectful tidak memperdulikan anaknya. Dimensi pola asuh terdiri dari parental responsiveness dan parental demandingness. Menurut Gafoor dan Kurukkan (2014), parental responsiveness adalah sikap menyesuaikan diri, mendukung, dan menyetujui tuntutan anak. Mereka juga peka pada kebutuhan anak dan mengekspresikan kasih sayang, kehangatan serta perhatian (Arnett, 2013). Orangtua yang responsive sering tersenyum, memuji, dan memberikan semangat pada anak-anaknya (Shaffer \& Kipp, 2014). Sementara itu, parental demandingness adalah tuntutan orangtua dengan cara mendisiplinkan anak yang tidak mematuhinya (Gafor \& Kurukkan, 2014). Orangtua menetapkan peraturan dan harapan dalam berperilaku serta meminta anak-anak untuk mematuhi mereka (Arnett, 2013). Orangtua dengan demandingness membatasi kebebasan berekspresi anak dengan menetapkan banyak peraturan. Orangtua secara aktif memantau perilaku anak untuk memastikan bahwa peraturan diikuti (Schaffer \& Kipp, 2014).

Di Indonesia, pola asuh orangtua berhubungan signifikan dengan: (a) kecerdasan spiritual anak (Utami, 2017); (b) sikap disiplin belajar siswa (Arifin \& Ummah, 2018; Murti, Murti, \& Suryani, 2015); (c) prestasi belajar siswa (Ningrum, 2016); dan (d) tumbuh kembang anak (Puspita, 
Makmuriana, \& Mariani, 2014). Kebanyakan orangtua cenderung menerapkan pola asuh yang otoriter di suku Melayu Palembang (Khodijah, 2018) dan pola asuh demokratis di Malang (Hidayah, Yunita, \& Utami, 2013). Selain itu, pola asuh juga dapat berpengaruh terhadap kesejahteraan psikologis remaja.

Selain pola asuh, kenakalan remaja juga tidak dapat dipisahkan dengan kualitas hidup. Kualitas hidup adalah persepsi individu mengenai posisinya dalam kehidupannya yang ditinjau dari konteks budaya dan sistem nilai, tujuan, harapan, perhatian dan standar yang ditetapkannya (World Health Organization Quality of Life Group, dalam Fitriana et.al, 2012). Hal ini sejalan dengan pendapat Gill \& Feinstein (dalam Rachmawati, 2013) yang mendefinisikan kualitas hidup sebagai persepsi individu tentang posisinya dalam kehidupan, hubungannya dengan sistem budaya dan nilai setempat, cita-cita, pengharapan, dan pandangan-pandangannya yang merupakan pengukuran multidimensi dan tidak terbatas hanya pada efek fisik maupun pengobatan psikologis. Kualitas hidup merupakan suatu bentuk multidimensional dengan tiga konsep kualitas hidup yakni informasi yang dibutuhkan untuk kesejahteraan fisik, kemampuan fungsional, dan kesejahteraan emosi atau sosial, menilai celah antara keinginan atau harapan dengan sesuai kemampuan untuk melakukan perubahan dalam diri (Ware dalam Rachmawati, 2013). Berdasarkan paparan diatas, maka kualitas hidup dapat disimpulkan sebagai penilaian individu terhadap posisinya di kehidupan dalam konteks budaya dan sistem nilai di mana ia hidup, berkaitan dengan tujuan, harapan, standar serta hal yang menjadi perhatian individu. Kualitas hidup seseorang dapat ditinjau dari kebutuhan manusia baik secara objektif maupun subjektif. Kualitas hidup berkaitan dengan kebutuhan manusia secara objektif dan persepsi individu atau kelompok mengenai kesejahteraan subjektif (Costanza et al., 2007). Selanjutnya Koot dan Wallander (2001) mengatakan bahwa kualitas hidup adalah kombinasi dari kesejahteraan dalam berbagai aspek yang menonjol pada suatu zaman dan kebudayaan seseorang yang dinilai secara objektif dan subjektif, dengan tetap mengikuti standar universal dari hak asasi manusia.

Kualitas hidup remaja dapat dipengaruhi oleh beberapa factor. Menurut Dodoh Khodijah, Elina Lukman, Mumun Munigar dalam penelitian 'Obesitas Dengan Kualitas Hidup Remaja', menunjukan bahwa remaja semakin bertambah usia maka kualitas hidupnya semakin rendah. Hasil ini sejalan dengan temuan Frisen (2007) yang menyatakan bahwa semakin usia remaja bertambah maka penilaian kualitas hidup mereka semakin negatif (Frisen, 2007). Remaja awal lebih positif dan kurang kritis karena remaja awal belum mengalami banyak tekanan hidup. Sementara remaja tengah atau akhir lebih banyak terpapar dengan pengalaman dan tekanan yang lebih banyak, antara lain peningkatan tekanan akademik, sosial dan emosional.

Kualitas hidup remaja banyak ditentukan oleh orang tua atau wali karena remaja masih membutuhkan pengasuhan dan dukungan keluarga melalui pola asuh sejak awal kehidupannya. Kehidupan dan perkembangan manusia tidak terlepas dari interaksi dengan manusia lainnya. Mead (dalam Sunarto, 2004) mengatakan bahwa pada awal kehidupan manusia, interaksi seorang anak umumnya terbatas pada keluarga terutama Ayah dan Ibu. Salah satu tahap perkembangan manusia yang cukup rentan adalah masa remaja (King, 2011). Di satu sisi, remaja dapat menghasilkan prestasi-prestasi yang membanggakan. Hal ini terbukti dari ratusan medali emas, perak, dan perunggu yang telah diraih kaum pelajar remaja Indonesia (Suhanda, 2016). Namun di sisi lain, perilaku remaja juga dianggap potensial untuk mengalami kenakalan karena identitas diri yang ditunjukkan kerap kali berlebihan (Asnizar, 2017). Remaja melakukan perilaku-perilaku tersebut karena rendahnya tingkat kepuasan hidup (Valois, Zullig, Huebner, dan Drane, dalam Oladipo, Adenaike, Adejumo, dan Ojewumi, 2013). Menurut teori 
perkembangan psikososial Erikson (dalam Santrock, 2005) remaja berada dalam tahap identity versus identity confusion. Pada tahap ini remaja melakukan pencarian jati diri. Pada proses ini seringkali remaja menolak nasehat dan nilai yang diberikan oleh orangtua, padahal remaja masih tetap membutuhkan dukungan dari orangtua untuk mengatasi masalah (Feist \& Feist, 2009; Maharani \& Andayani, 2003). Remaja seringkali terlibat masalah, salah satunya adalah menjadi korban kekerasan fisik. Selain remaja dapat menjadi korban kekerasan fisik, dinyatakan bahwa sebagian remaja yang tidak dapat mengontrol tingginya agresi fisik dapat berpotensi untuk membunuh orang lain (Sullivan, Farrel, \& Kliewer, 2006; Taylor, Peplau, \& Sears, 2006). Sebuah kasus di tahun 2008 terjadi ketika remaja (inisial R) telah membunuh sekitar 11 orang (Wisnubrata, 2010). Psikiater mengatakan R merasa kurang diperhatikan, memiliki masalah ekonomi di keluarga, dan ketidakcocokan serta rasa tak suka dengan Ibu (Burhani, 2008). Hal ini dibenarkan oleh kakak tiri R, bahwa sejak kecil R mengalami kekerasan dari Ibunya. Hal tersebut menyebabkan di usia 13 tahun $\mathrm{R}$ mengalami tekanan kejiwaan akibat memendam kebencian kepada Ibunya. Berdasarkan ini, diketahui bahwa pola asuh orangtua mempengaruhi perkembangan anak. Oleh karena itu, pola asuh berperan penting terhadap karakteristik dan perilaku remaja (Abrhiem, 2014). Pola asuh merupakan pola yang ditunjukkan orangtua terhadap anak-anaknya dalam menjalin relasi (Arnett, 2013).

Menurut Psikolog Adelina Syarief, SE, MPsi, kenakalan remaja disebabkan diri sendiri dan lingkungan sehingga terjadi perilaku yang menyimpang. Dia juga menyatakan bahwa anak yang tidak merasa nyaman di rumah akan mudah terpengaruh lingkungan dengan ajakan teman yang melakukan hal yang destruktif. "Penyebabnya bisa dari sifat bawaan atau dari keluarga misalnya orangtua yang terlalu sibuk, kurangnya komunikasi atau perceraian," ujar Adel.

Dalam upaya meningkatkan kemajuan bangsa Indonesia perlu diperhatikan semua lapisan masyarakat, khususnya para remaja yang akan menjadi tiang tonggak bangsa Indonesia di masa mendatang. Seperempat dari penduduk Indonesia merupakan anak-anak dan remaja. Melihat hal tersebut, maka peneliti tertarik meneliti hal ini karena kehidupan remaja tidak terlepas dari pola asuh orangtua. Peneliti menduga bahwa ada hubungan antara pola asuh orangtua dengan kualitas hidup remaja perkotaan. Apakah terdapat perbedaan kualitas hidup remaja perkotaan ditinjau dari peranan pola asuh orangtua?

\section{METODE PENELITIAN}

\section{Partisipan dan prosedur penelitian}

Penelitian ini dilakukan dengan desain kuantitatif non-eksperimental. Pemilihan sampel dilakukan secara purposive sampling, artinya subyek memenuhi kriteria yang sesuai dengan rancangan peneliti. Peneliti mencari semua nama-nama Sekolah Negeri yang di Jakarta kemudian memilih Sekolah Negeri yang tidak terlalu jauh jaraknya dari kampus tempat peneliti bekerja dan menghubungi pihak administrasi kedua Sekolah Negeri di Jakarta. Setelah alat ukur siap, maka dilakukan pengambilan data dengan cara masuk ke kelas partisipan, sesuai waktu yang telah diizinkan oleh pihak sekolah SMA Negeri. Teknik pengambilan sampel dalam penelitian ini dilakukan dengan cara memberikan kuesioner kepada siswa dengan rentang usia 14-21 tahun baik pria dan wanita yang bersekolah di SMA Negeri di Sekolah X dan Sekolah Y, Jakarta. Sebelum menyebarkan kuesioner, peneliti memperkenalkan diri dan menjelaskan tentang informed consent, dan menjamin kerahasiaan data. Selanjutnya, peneliti menjelaskan instruksi pengisian kuesioner. Subyek mengisi informed consent dan biodata diri terlebih dahulu, kemudian dilanjutkan dengan mengisi kuesioner pola asuh ayah, pola asuh ibu, dan kualitas hidup. Setelah semua kuesioner selesai diisi dan telah dikembalikan, peneliti mengucapkan dan memberikan souvenir sebagai tanda terima kasih kepada para subyek. Peneliti memperoleh data sebanyak 381 
data, terdiri dari 147 pria dan 234 wanita. Dalam mengolah data, peneliti menggunakan teknik analisis data kuantitatif dengan menggunakan program SPSS versi 22 for windows.

\section{Pengukuran}

Pola asuh merupakan variabel independen pada penelitian ini. Ada tiga jenis pola asuh menurut Baumrind (dalam Lilienfeld, Lynn, Namy, \& Woolf, 2009; dalam Papalia, Olds, \& Feldman, 2009) yakni authoritarian, authoritative, dan permissive. Melalui penelitian, Maccoby dan Martin (dalam Papalia et al., 2009) berhasil mengidentifikasi pola asuh keempat yakni neglectful. Alat ukur pola asuh orang tua yang terdiri atas pola asuh ayah dan ibu dan dikembangkan oleh Wijaya, Dewi dan Sahrani (2014) dari teori Baumrind (1971). Alat ukur pola asuh terdiri dari 2 bagian yaitu pola asuh ayah dan pola asuh ibu yang masing-masing terdiri dari 28 butir. Dimensi pertama adalah responsiveness dengan 8 butir positif dan 8 butir negatif. Dimensi kedua adalah demandingness dengan 6 butir positif dan 6 butir negatif. Peneliti melakukan uji reliabilitas alat ukur pola asuh Ayah dan pola asuh Ibu. Pada pola asuh ayah, tidak ada butir yang dibuang pada dimensi responsiveness sehingga butir tetap berjumlah 16 butir. Nilai koefisien alpha cronbach yaitu 0.902. Sementara itu, dimensi demandingness terdiri atas 12 butir dengan koefisien alpha cronbach sebesar 0.819. Uji reliabilitas pola asuh Ibu menunjukan bahwa dimensi responsiveness memiliki 16 butir dengan koefisien alpha cronbach sebesar 0.888 . Selanjutnya dimensi demandingness terdiri atas 12 butir dengan nilai koefisien alpha cronbach sebesar 0.774 .

Tabel 1. Dimensi Pola Asuh

\begin{tabular}{llll}
\hline & \multicolumn{3}{c}{ Demandingness } \\
\hline Responsiveness & High & High & Aow \\
\hline & Low & Authoritative & Permissive \\
\hline
\end{tabular}

Kualitas hidup merupakan variabel dependen pada penelitian ini. Kualitas hidup remaja (YQOL) dapat diukur. Pemerintah Brazil yang terdiri dari Giovanni Abrahao Salum Junior, Luciano Isonlan, Gisele Gus Manfro dan Marcelo Fleck membuat alat ukur YQOL yang terdiri dari 4 domain yaitu: 1) Domain pribadi yang merupakan penilaian terhadap diri sendiri (10 item); 2) Domain relasional yang merupakan penilaian terhadap persahabatan, lingkungan rumah, tetangga atau sekolah (14 item); 3) Domain lingkungan yang merupakan penilaian interaksi dengan lingkungan (10 item); dan 4) Domain kulitas hidup secara keseluruhan, yang merupakan penilaian secara umum mengenai tujuan hidup (3 item). Dengan demikian, alat ukur ini memiliki total 41 butir soal yang mengukur YQOL. Alat ukur kualitas hidup menggunakan skala Likert dengan 4 pilihan. Peneliti melakukan uji reliabilitas pada seluruh butir (41 butir). Nilai koefisien alpha cronbach yaitu 0.908. Peneliti juga menguji reliabilitas setiap domain. Domain pribadi terdiri atas 14 butir dengan koefisien alpha cronbach sebesar 0.718. Domain relasional terdiri atas 14 butir dengan koefisien alpha cronbach sebesar 0.878. Domain lingkungan terdiri atas 10 butir dengan koefisien alpha cronbach sebesar 0.817. Domain kualitas hidup secara umum terdiri atas 3 butir dengan nilai koefisien alpha cronbach sebesar 0.772 .

Tabel 2. Hasil Uji Reliabilitas Dimensi Alat Ukur Kualitas hidup

\begin{tabular}{llll}
\hline Domain & Butir & Mean Empirik & Alpha Cronbach \\
\hline Pribadi & 14 & 68.55 & 0.718 \\
Relasional & 14 & 80.50 & 0.878 \\
Lingkungan & 10 & 83.79 & 0.817 \\
Kualitas hidup secara keseluruhan & 3 & 83.95 & 0.772 \\
\hline
\end{tabular}




\section{HASIL DAN PEMBAHASAN Gambaran partisipan penelitian}

Berdasarkan kategori jenis kelamin, dari total 381 partisipan, ada 234 (61.4\%) partisipan perempuan dan $147(38.6 \%)$ partisipan laki-laki. Partisipan paling banyak berada pada usia middle adolescence (usia 14-17tahun) dengan jumlah 366 (96.1\%) partisipan. Sementara itu, ada 15 (3.9\%) partisipan late adolescence (usia 18-21 tahun).

\section{Gambaran kualitas hidup}

Peneliti melakukan perbandingan mean empirik dengan mean hipotetik pada 4 domain. Mean hipotetik untuk seluruh domain adalah 77.47. Pada domain kualitas hidup secara umum, rata-rata skor partisipan termasuk tinggi ( mean empirik $=83.95>$ mean hipotetik $=77.47$ ). Mean empirik domain kualitas hidup secara pribadi adalah rendah (mean empiric $=68.55<77.47$ ) dan yang terendah dibandingkan domain lainnya. Domain kualitas hidup secara relasi memiliki mean empirik $=80.50$, sehingga rata-rata skor subyek pada dimensi ini dapat dikatakan tinggi (80.51 > 77.47). Sementara itu, domain kualitas hidup secara lingkungan memiliki mean empirik $=83.79$, sehingga rata-rata skor partisipan pada domain ini tetap dapat dikatakan tinggi $(83.79>77.47)$.

\section{Gambaran pola asuh ayah dan ibu}

Pola asuh Ayah dan Ibu masing-masing memiliki dua dimensi yaitu responsiveness dan demandingness. Ada empat tipe pada pola asuh Ayah dan Ibu, yaitu authoritative, authoritarian, permissive, dan neglectful. Jika skor tinggi pada responsiveness dan demandingness, maka tergolong dalam authoritative. Kemudian, jika skor rendah pada responsiveness dan tinggi pada demandingness, maka dapat digolongan ke dalam authoritarian. Jika skor tinggi pada responsiveness dan rendah pada demandingness, digolongkan ke dalam permissive. Terakhir, jika skor rendah pada responsiveness dan demandingness, maka digolongkan ke dalam neglectful.

Tabel 3. Tabel Tipe Pola Asuh

\begin{tabular}{llll}
\hline & \multicolumn{3}{c}{ Demandingness } \\
\hline Responsiveness & High & High & Low \\
\hline & Low & Authoritative & Permissive \\
\hline
\end{tabular}

Pada alat ukur pola asuh Ayah dan Ibu, peneliti juga melakukan perbandingan antara mean hipotetik dan mean empirik untuk mengetahui posisi skor di suatu dimensi. Setiap dimensi pada pola asuh Ayah dan Ibu memiliki mean hipotetik $=3.00$. Pada dimensi responsiveness, mean empirik pola asuh Ayah lebih besar dari mean hipotetik (3.64 > 3.00). Mean empirik pola asuh Ibu juga lebih besar dari mean hipotetik $(4.00>3.00)$. Dengan demikian, rata-rata skor pola asuh Ayah dan Ibu pada dimensi ini dapat dikatakan tinggi. Dimensi demandingness juga memiliki mean empirik = 3.00. Mean empirik pola asuh Ayah lebih besar dari mean hipotetik (3.53 > 3.00). Mean empirik pola asuh Ibu juga lebih besar daripada mean hipotetik $(3.66>3.00)$. Dengan demikian, rata-rata skor partisipan pada dimensi ini dapat dikatakan tinggi.

Tinggi atau rendahnya skor pada kedua dimensi ini menentukan jenis pola asuh Ayah dan Ibu partisipan. Berdasarkan data yang didapat, diketahui bahwa $283(74.3 \%)$ partisipan memiliki Ayah dengan pola asuh authoritative. Jumlah partisipan yang memiliki Ayah dengan pola neglectful paling sedikit, yaitu 26 (6.8\%) partisipan. Sementara itu, pada data pola asuh Ibu, partisipan terbanyak terbanyak memiliki Ibu dengan pola asuh authoritative, yaitu $330(86.6 \%)$ partisipan. Pola asuh yang paling sedikit pada data pola asuh Ibu adalah authoritarian dengan jumlah $10(2.6 \%)$ partisipan. 
Tabel 4. Gambaran Data Pola Asuh Ayah dan Pola Asuh Ibu

\begin{tabular}{lcccc}
\hline Tipe Pola Asuh & $\begin{array}{l}\text { Pola Asuh Ayah } \\
\text { Frekuensi }\end{array}$ & Persentase & $\begin{array}{l}\text { Pola Asuh Ibu } \\
\text { Frekuensi }\end{array}$ & Persentase \\
\hline Authoritative & 283 & 74.3 & 330 & 86.6 \\
Authoritarian & 33 & 8.7 & 10 & 2.6 \\
Permissive & 39 & 10.2 & 30 & 7.9 \\
Neglectful & 26 & 6.8 & 11 & 2.9 \\
\hline Total & 381 & 100 & 381 & 100 \\
\hline
\end{tabular}

\section{Analisis data utama}

Berdasarkan uji one sample $K$-S diketahui bahwa variabel kualitas hidup berdistribusi normal. Hal tersebut dipastikan oleh nilai $p$ pada pengujian Kolmogorov-Smirnov yang lebih besar dari $0.05(0.089>0.05)$.

\section{Uji beda kualitas hidup ditinjau dari pola asuh Ayah dan Ibu}

Pada penelitian ini terdapat empat jenis pola asuh yang ingin dilihat perbedaan nilai rata-ratanya. Karena itu digunakan teknik analisis uji beda one-way ANOVA. Hasil menunjukan ada perbedaan signifikan pada kualitas hidup ditinjau dari pola asuh Ayah $(F=6.146 ; p=0.000<0.05)$. Ditemukan pula perbedaan signifikan pada kualitas hidup ditinjau dari pola asuh Ibu $(F=$ 10.203; $p=0.000<0.05)$. Analisa deskriptif pola asuh Ayah menunjukan bahwa dimensi dengan mean terbesar adalah authoritative (78.48) dan dimensi dengan mean terkecil adalah neglectful (72.28). Sementara itu, analisa deskriptif pola asuh Ibu menunjukan bahwa dimensi dengan mean terbesar adalah authoritative (78.30) dan dimensi dengan mean terkecil adalah neglectful (66.45).

Tabel 5. Analisa Deskriptif dari Hasil Uji Beda Kualitas Hidup

\begin{tabular}{lll}
\hline Jenis Pola Asuh & Mean Pola Asuh Ayah & Mean Pola Asuh Ibu \\
\hline Authoritative & 78.48 & 78.30 \\
\hline Authoritarian & 74.05 & 70.51 \\
\hline Permissie & 76.50 & 74.72 \\
\hline Neglectful & 72.28 & 66.45 \\
\hline
\end{tabular}

\section{Analisis data tambahan}

Uji beda variabel kualitas hidup ditinjau dari jenis kelamin, usia, dan pola asuh Ayah dan Ibu

Peneliti melakukan uji beda kualitas hidup ditinjau dari jenis kelamin, usia, dan pola asuh Ayah dan Ibu. Hasil uji beda ditinjau dari jenis kelamin dilakukan dengan teknik Independent Sample T-test. Hasil uji menunjukan $\mathrm{F}=0.771$ dan $p=0.381$. Nilai $p$ lebih besar dari $0.05(0.381>0.05)$ yang berarti tidak ada perbedaan kualitas hidup ditinjau dari jenis kelamin. Sementara itu, uji beda kualitas hidup ditinjau dari usia digunakan dengan teknik one-way ANOVA. Hasil uji menunjukan $\mathrm{F}=0.998$ dan nilai $p=0.419$. Nilai $p$ lebih besar dari $0.05(0.419>0.05)$ yang berarti tidak ada perbedaan kualitas hidup pada remaja ditinjau dari usia. Uji beda dimensi kualitas hidup ditinjau dari pola asuh Ayah dan Ibu menunjukan nilai $p$ di bawah 0.05. Dengan demikian, maka diketahui terdapat perbedaan dimensi kualitas hidup ditinjau dari pola asuh ayah dan pola asuh ibu.

\section{Uji beda pola asuh Ayah dan Ibu ditinjau dari jenis kelamin dan usia}

Uji beda berdasarkan jenis kelamin dilakukan dengan Independent Sample T-test. Hasil menunjukan $\mathrm{F}=5.057$ dan $p=0.025$. Nilai $p$ lebih kecil dari $0.05(0.025<0.05)$ yang berarti ada perbedaan pola asuh ayah ditinjau dari jenis kelamin. Hasil uji beda pada pola asuh Ibu diperoleh $\mathrm{F}=1.071$ dan $p=0.301$. Nilai $p$ lebih besar dari $0.05(0.301>0.05)$ yang berarti tidak ada perbedaan pola asuh ibu ditinjau dari jenis kelamin. Uji beda pola asuh orangtua ditinjau dari 
usia dilakukan dengan one-way ANOVA. Setelah dilakukan uji beda, diketahui nilai $\mathrm{F}=0.934$ dan nilai $p=0.459$. Nilai $p$ lebih besar dari $0.05(0.459>0.05)$ yang berarti tidak terdapat perbedaan pola asuh orangtua baik ayah ataupun pola asuh ibu terhadap remaja ditinjau dari usia.

\section{Uji beda domain kualitas hidup remaja ditinjau dari pola asuh Ayah}

Hasil pengolahan data menunjukan bahwa hanya domain pribadi dengan $p$ di atas 0.05 , yang berarti tidak ada perbedaan domain kualitas hidup pribadi ditinjau dari pola asuh Ayah. Tetapi untuk kualitas hidup remaja domain relasional, lingkungan dan kualitas hidup secara keseluruhan, nilai $p$ di bawah 0.05 berarti ada perbedaan kualitas hidup remaja domain relasional, lingkungan dan kualitas hidup secara keseluruhan remaja ditinjau dari pola asuh Ayah.

\section{Uji beda domain kualitas hidup remaja ditinjau dari pola asuh Ibu}

Pada bagian ini dilakukan uji beda domain kualitas hidup remaja ditinjau dari pola asuh Ibu. Hasil pengolahan data menunjukkan bahwa kualitas hidup remaja domain pribadi dan domain kualitas hidup secara keseluruhan, nilai $p$ di atas 0.05 , yang berarti tidak ada perbedaan kualitas hidup remaja domain pribadi dan domain kualitas hidup secara keseluruhan yang ditinjau dari pola asuh Ibu. Tetapi untuk kualitas hidup remaja domain relasional dan domain lingkungan, nilai p yang memiliki skor di bawah 0.05, yang berarti terdapat perbedaan kualitas hidup remaja domain relasional dan domain lingkungan yang ditinjau dari pola asuh ibu.

\section{KESIMPULAN DAN SARAN}

Analisis data menunjukan bahwa hipotesis penelitian di terima. Hasil penelitian menunjukan terdapat perbedaan kualitas hidup remaja perkotaan ditinjau dari peranan pola asuh orangtua. Kualitas hidup remaja banyak ditentukan oleh orang tua atau wali karena remaja masih membutuhkan pengasuhan dan dukungan keluarga melalui pola asuh sejak awal kehidupannya. Kehidupan dan perkembangan manusia tidak terlepas dari interaksi dengan manusia lainnya. Mead (dalam Sunarto, 2004) mengatakan bahwa pada awal kehidupan manusia, interaksi seorang anak umumnya terbatas pada keluarga terutama Ayah dan Ibu. Salah satu tahap perkembangan manusia yang cukup rentan adalah masa remaja (King, 2011). Di satu sisi, remaja dapat menghasilkan prestasi-prestasi yang membanggakan. Hal ini terbukti dari ratusan medali emas, perak, dan perunggu yang telah diraih kaum pelajar remaja Indonesia (Suhanda, 2016). Mead (dalam Sunarto, 2004) mengatakan bahwa pada awal kehidupan manusia, interaksi seorang anak umumnya terbatas pada keluarga terutama Ayah dan Ibu.

Penelitian ini diikuti oleh remaja perempuan sejumlah 61.4\% (234 org) lebih banyak dibandingkan dengan remaja laki-laki $38.6 \%$ (147). Tidak ada partisipan yang dari early adolescents, tetapi middle adolescents sebanyak 96,1\% (366 orang) dan late adolescents sebanyak 3.9\% (15 orang). Hasil menunjukan ada perbedaan signifikan pada kualitas hidup ditinjau dari pola asuh Ayah $(F=6.146 ; p=0.000<0.05)$ dan pada pola asuh $(F=10.203 ; p=$ $0.000<0.05)$. Analisis deskriptif dimensi pola asuh authoritative dengan mean terbesar $(78.48)$ pada ayah dan authoritative dengan mean terbesar (78.30) pada ibu; sedangkan mean terkecil neglectful (72.28) pada ayah dan mean terkecil neglectful (66.45) pada ibu. Penelitian ini memberi gambaran bahwa remaja dengan orangtua yang authoritative memiliki kualitas hidup yang tinggi, dimana orang tua mendorong dan juga memberikan batasan, remaja menjadi pribadi yang mandiri. Sementara, remaja dengan pola asuh orangtua yang neglectful memiliki kualitas hidup yang rendah, dimana kurang keterlibatan orangtua dalam kehidupan anak, remaja menjadi pribadi tidak mandiri, kurang kompeten bersosialisasi dan kurang pengendalian diri. Hasil studi ini didukung oleh temuan (Arifin \& Ummah, 2018) yang menyatakan bahwa pola asuh dapat 
mempengaruhi tingkat kepercayaan diri anak, performa dalam akademik, dan perilaku. Pola asuh juga dapat mempengaruhi pembentukan kecerdasan emosional (Hidayah, Yunita, \& Utami, 2013).

Pada analisis tambahan, tidak terdapat perbedaan kualitas hidup ditinjau dari jenis kelamin dan usia baik pada pola asuh ayah maupun pola asuh ibu. Hasil penelitian juga menunjukkan bahwa pola asuh authoritative, authoritarian dan neglectful ada hubungan dengan kualitas hidup remaja perkotaan. Namun pola asuh permissive tidak ada hubungan dengan kualitas hidup remaja perkotaan. Adanya temuan dari penelitian ini diharapkan memberi kontribusi kepada ilmu psikologi pendidikan dan perkembangan tentang kualitas hidup remaja perkotaan.

Selanjutnya, mengenai perbedaan kualitas hidup pada remaja, disarankan untuk menggunakan variable lain, misalnya regulasi diri maupun self-esteem. Selain itu, salah satu faktor yang memiliki kemungkinan berpengaruh terhadap kualitas hidup pada remaja adalah hal-hal yang terkait dalam pergaulan remaja. Penelitian serupa dapat dilakukan kepada subyek yang diasuh oleh orang selain orang tua kandung. Remaja pun diharapkan tetap mendekatkan diri pada keluarga agar orangtua tetap dapat membina kedekatan. Pihak sekolah pun perlu mensosialisasikan kepada orang tua tentang pola asuh authoritative. Pihak sekolah dapat memberikan kesempatan kepada anak untuk bertukar pikiran dengan orang tua, membina hubungan yang lebih baik dengan orang tua, agar mereka mendapat tuntunan yang lebih baik dalam segala aspek kehidupan. Dengan pola asuh authoritative, diharapkan orangtua dapat menjalin hubungan yang harmonis serta membimbing remaja agar mereka memiliki kualitas hidup yang tinggi.

\section{Ucapan Terima Kasih (Acknowledgement)}

Terima kasih kepada Ketua LPPM bapak Ir. Djap Tjie Beng, Dr. Rostiana, M.Psi., Psikolog, dekan Fakultas Psikologi, dan Dr. Fransisca I.R. Dewi, Manager Penelitian dan yang telah mendukung kami dalam penelitian ini melalui tugas penelitian hibah Internal Universitas Tarumanagara. Terima kasih juga kami sampaikan kepada partisipan Sekolah Negeri X dan Sekolah Negeri Y yang telah mengizinkan peneliti untuk mengambil data.

\section{REFERENSI}

Abrhiem, T. H. (2014). The role of parenting styles in psychosocial development of adolescents. Business and Management Review, 3(11), 47-52.

Ardini, S. (2012). Tingkat kecerdasan emosional pada remaja ditinjau dari persepsi pola asuh orangtua (Skripsi tidak dipublikasikan). Jakarta.

Arifin, A. A., \& Ummah, D. M. (2018). Pengaruh pola asuh orang tua tunggal dalam keluarga terhadap kedisiplinan belajar siswa. JURKAM: Jurnal Konseling Andi Matappa, 2(1), 5257. Diunduh dari https://journal.stkip-andimatappa.ac.id/index.php/jurkam/article/download/93/pdf

Arnett, J. J. (2013). Adoescence and emerging adulthood (5 ${ }^{\text {th }}$ ed.). Upper Saddle River, NJ: Pearson.

Asnizar, E. (2017, Juni 12). Remaja: Kelompok rentan perilaku beresiko. Aceh Journal National Network. Diunduh dari http://www.ajnn.net/news/remaja-kelompok-rentan-perilakuberesiko/index.html

Berns, R. M. (2013). Child, family, school, community: Socialization and support (9 ${ }^{\text {th }}$ ed.). Belmont, CA: Wadsworth.

Berk, L. E. (2014). Development through life span (6 $6^{\text {th }}$ ed.). Upper Saddle River, NJ: Pearson. 
Baumrind, D. (1971). Current patterns of parental authority. Development Psychology Monograps, 4(1), 1-103. https://doi.org/10.1037/h0030372

Burhani, R. (2008, Agustus, 2). Mengapa ryan membunuh?. Antaranews. Diunduh dari http://www.antaranews.com/berita/111431/mengapa-ryan-membunuh.

Costanza, R., Fisher, B., Ali, S., Beer, C., Bond, L., Boumans, R., ... Snapp, R. (2007). Quality of life: An approach integrating opportunities, human needs, and subjective well-being. Ecological Economics, 61(2-3), 267-276. doi:10.1016/j.ecolecon.2006.02.023

Departemen Pendidikan Nasional. (2008). Kamus besar bahasa indonesia pusat bahasa (4 ${ }^{\text {th }} \mathrm{ed}$.). Jakarta: PT. Gramedia Pustaka Utama.

Feist, J., \& Feist, G. J. (2009). Theories of personality ( $7^{\text {th }}$ ed.). New York, NY: McGraw-Hill.

Fitriana, N. A., \& Ambarini, T. K. (2012). Kualitas hidup pada penderita kanker serviks yang menjalani pengobatan radioterapi. Jurnal Psikologi Klinis dan Kesehatan Mental, 1(2), 123-129. Diunduh dari http://journal.unair.ac.id/filerPDF/110810265_11v.pdf

Frisen, A. (2007). Measuring health-related quality of life in adolescence. Acta Pediatrica, 96(7), 963-968. https://doi.org/10.1111/j.1651-2227.2007.00333.x

Gafor, K. A., \& Kurukkan, A. (2014). Construction and validation of scale of parenting style. Guru Journal of Behavioral and Social Sciences, 2(4), 315-323. Diunduh dari https://eric.ed.gov/?id=ed553154

Hidayah, R., Yunita, E., \& Utami, Y. W. (2013). Hubungan pola asuh orangtua dengan kecerdasan emosional anak usia prasekolah (4-6 tahun) di TK Senaputra Kota Malang. Jurnal Keperawatan, 4(2). 131-135. Diunduh dari http://ejournal.umm.ac.id/index.php/keperawatan/article/view/2363

King, L., A. (2011). The science of psychology: An appreciative view. New York, NY: McGrawHill.

Khodijah, N. (2018). Pendidikan karakter dalam Kultur Islam Melayu (studi terhadap pola asuh orang tua, faktor-faktor yang mempengaruhinya, dan pengaruhnya terhadap religiusitas remaja pada Suku Melayu Palembang). Tadrib: Jurnal Pendidikan Agama Islam, 4(1), 21-39. Diunduh dari http://jurnal.radenfatah.ac.id/index.php/Tadrib/article/view/1949

Koot, H. M., \& Wallander, J. L. (2001). Quality of life in child and adolescent illness: Concepts, methods and findings. London, UK: Brunner-Routledge.

Lawrence Erlbaum Associates, Inc. (2002). Handbook of parenting (4 $4^{\text {th }} e d$.). New Jersey: Lawrence Erlbaum Associates.

Maharani, O. P., \& Andayani, B. (2003). Hubungan antara dukungan sosial ayah dengan penyesuaian sosial pada remaja laki-laki. Jurnal Psikologi, 30(1), 23-35. Diunduh dari https://jurnal.ugm.ac.id/jpsi/article/view/7030

Murti, A. M., Murti, B., \& Suryani, N. (2015). Hubungan kecerdasan emosi dan pola asuh orang tua dengan kedisiplinan belajar mahasiswa Akademi Kebidanan Yappi Sragen (Relationships parenting emotional intelligence and parents student learning by discipline Academy of Midwifery Yappi Sragen). IJMS-Indonesian Journal on Medical, 2(1), 4651. Diunduh dari http://www.ejournal.ijmsbm.org/index.php/ijms/article/view/18

Ningrum, W. R. (2016). Pengaruh peranan dan pola asuh orang tua terhadap hasil belajar siswa Sekolah Dasar Negeri (SDN) di Kecamatan Bogor Barat. Jurnal Pendidikan, 17(2), 129137. Diunduh dari https://jurnal.ut.ac.id/index.php/jp/article/view/273

Oladipo, S. E., Adenaike, F. A., Adejumo, A. O., \& Ojewumi, K. O. (2013). Psychological predictors of life satisfaction amoung undergraduates. Procedia: Social and Behavioral Science, 82, 292-297. doi: 10.1016/j.sbspro.2013.06.263

Olson, D. H., DeFrain, J., \& Skogrand, L. (2011). Marriages and families ( $7^{\text {th }}$ ed.). New York, NY: McGraw Hill. 
Papalia, D. E., Olds, S. W., \& Feldman, R. D. (2009). Human development (11 ${ }^{\text {th }}$ ed.). New York, NY: McGraw-Hill.

Puspita, D., Makmuriana, L., \& Mariani, A. R. (2014). Hubungan pola asuh orangtua terhadap tumbuh kembang anak dan kejadian obesitas di Sekolah Dasar Swasta Bruder Melati Pontianak. Jurnal Keperawatan \& Kesehatan, 5(3), 39-46. Diunduh dari http://jurnalstikmuh-ptk.id/index.php/JK2/article/view/15

Rice, F. P., \& Dolgin, K. G. (2008). The adolescent: Development, relationships, and culture. Boston: Allyn and Bacon.

Santrock, J. W. (2005) Child development. New York, NY: McGraw-Hill.

Santrock, J. W. (2015). Life-span development (15 ${ }^{\text {th }}$ ed.). New York, NY: McGraw Hill.

Shaffer, D. R., \& Kipp, K. (2014). Developmental psychology: Childhood and adolescence ( $9^{\text {th }}$ ed.). Belmont, CA: Wadsworth.

Steinberg, L. D., Vandell, D., \& Bornstein, M. H. (2011). Development: Infancy through adolescence. Belmont, USA: Wadsworth, Cengage Learning.

Suhanda, I. (2016, Juni 4). Sah... Prestasi belajar Indonesia diakui dunia. Kompas. Diunduh dari https://edukasi.kompas.com/read/2016/06/24/17170011/Sah.Prestasi

Sunarto, K. (2004). Pengantar sosiologi (Edisi Revisi). Jakarta: Lembaga Penerbit Fakultas Ekonomi Universitas Indonesia.

Sullivan, T. N., Farrel, A. D., \& Kliewer, W. (2006). Peer victimization in early adolescence: Association between physical and relational victimization and drug use, aggression, and delinquent behaviors among urban middle school students. 18(1), 119-137. doi:10.1017/S095457940606007X

Taufik, M. (2018, September 16). Tawuran antarpelajar, perilaku anomali. Itjen Kemendikbud. Diakses dari https://itjen.kemdikbud.go.id/public/post/detail/tawuran-antarpelajarperilaku-anomali

Taylor, S. E., Peplau, L. A., \& Sears, D. O. (2006). Social psychology (12 ${ }^{\text {th }}$ ed.). New Jersey: Pearson Education, Inc.

Utami, L. K. D. (2017). Hubungan antara tingkat pendidikan dan pola asuh orang tua dengan kecerdasan spiritual anak sekolah menengah pertama di Kecamatan Mengwi. Jurnal Penelitian Agama Hindu, 1(2), 123-129. Diunduh dari http://ejournal.ihdn.ac.id/index.php/JPAH/article/view/226

Wijaya, E., Dewi, F. I. R., \& Sahrani, R. (2014). Alat ukur pola asuh orang tua berdasarkan teori Baumrind (1971). Fakultas Psikologi Universitas Tarumanagara: Bagian riset dan pengukuran.

Wisnubrata, A. (2010, Oktober, 17). Wah, ryan jagal nikahi anak pengusaha. Kompas Megapolitan. Diunduh dari http://megapolitan.kompas.com/read/ 2010/10/17/10561677/ Wah..Ryan.Jagal.Nikahi.Anak.Pengusaha-5 